\title{
Assessing the groundwater degree of contamination on the western slope of Ada Tepe
}

\section{Определяне степента на замърсяване на подземните води в района на западния склон на Адатепе}

\section{Tanya Vasileva \\ Таня Василева}

Geological Institute, BAS, Acad. G. Bonchev str., bl. 24, 1113 Sofia, Bulgaria; E-mail: tanyav@geology.bas.bg

\begin{abstract}
In the present article, a method has been suggested for the assessment of groundwater pollution by means of a groundwater contamination index. The practical applicability of this index has been tested in the vicinity of Ada Tepe Mining Facility near Krumovgrad in Southeast Bulgaria. The index takes into account both those parameters exceeding the permissible amounts, and the concentrations of those contaminants exceeding those limits according to specific standards. The factors affecting the quality of groundwater can be described as natural (geogenic): geological, climatic, topographic, or biological and anthropogenic - pollution from agricultural or industrial activities, sewerage infrastructure, etc.
\end{abstract}

Keywords: contamination index, degree of contamination, groundwater contamination.

\section{Въведение}

България се отличава с неравномерно разпространение на подземните си води. Това налага тяхното ефективно използване и минимално въздействие върху качеството им. Целта на доклада е да се покаже метод за определяне на степента на замърсеност на подземните води, чрез използването на данни от физико-химични анализи. Досега за цялата територия на България, както и за отделни участъци, са извършвани много проучвания за качествата на подземните води. Те са били насочени към конкретни обекти и площи, като характерното за досегашните изследвания е, че те се основават на оценки по отделни показатели, без да се търси интегриран резултат. В изследването е представен метод за оценка степента на замърсеност или индекса на замърсяване $\left(\mathrm{C}_{\mathrm{D}}\right)$ на подземните води, разработен при геоложкото проучване на Словашката република от Bodišand и Rapant (Rapant et al., $1995)$ и допълнително доразвит при геоложкото проучване на Финландия (Backman et al., 1998).

\section{Методология за определяне на степента на замърсяване на подземните води $\left(\mathrm{C}_{\mathrm{D}}\right)$}

Индексът на замърсяване (степента на замърсяване) в своята същност представлява една интегрирана оценка на химичния натиск (замърся- ването) при наличието на показатели с концентрации, надвишаващи пределната стойност. Методът отчита както броя на показателите, които надвишават горните допустими концентрации, дадени в стандарта, така и частта от концентрацията, надвишаваща тези стойности. Изчисляването на степента на замърсяване на подземните води се прави за всяка една от анализираните проби поотделно и като сума от факторите на замърсяване (Backman et al., 1998), а именно:

$$
\mathrm{C}_{\mathrm{D}}=\sum_{\mathrm{i}=1}^{\mathrm{n}}\left(\frac{\mathrm{C}_{\mathrm{Ai}}}{\mathrm{C}_{\mathrm{Ni}}}-1\right) \text {, }
$$

където: $\mathrm{C}_{\mathrm{D}}$ - степен на замърсяване; $\mathrm{C}_{\mathrm{Ai}}$ - аналитичната стойност на $\mathrm{i}^{\text {-тия }}$ компонент; $\mathrm{C}_{\mathrm{Ni}}-$ прагова стойност на $\mathrm{i}^{\text {-тия }}$ компонент.

Изразьт в скобите в уравнение (1) представлява фактор на замърсяване $\left(\mathrm{C}_{\mathrm{F}}\right)$ за всеки наблюдаван параметър с концентрация над пределната стойност, определена в стандарта или:

$$
\mathrm{C}_{\mathrm{Fi}}=\frac{\mathrm{C}_{\mathrm{Ai}}}{\mathrm{C}_{\mathrm{Ni}}}-1,
$$

където: $\mathrm{C}_{\mathrm{Fi}}$ е фактор на замърсяване на $\mathrm{i}^{\text {-тия }}$ компонент. Или параметърът „фактор на замърсяване“ отчита въздействието на дадения ингредиент.

По степен на замърсяване подземните води ce отделят в три групи (Backman et al., 1998): 
Таблица 1. Данни за мониторингов пункт през 2017 г. - сондаж EGW03

\begin{tabular}{lccccc}
\hline Показател & Март & Юни & Октомври & Декември & Стандарт*, mcg/l \\
\hline Mn, mcg/l & 150 & 303 & 315 & 198 & 50 \\
Fe, mcg/l & 530 & 176 & 1320 & 155 & 200 \\
As, mcg/l & 40 & 9,1 & 46 & $<4$ & 10 \\
Нефтопродукти, mcg/1 & 149 & $<20$ & $<20$ & 628 & 50 \\
\hline $\mathrm{C}_{\mathrm{D}}$ индекс & 8,6 & 5,1 & 14,5 & 14,3 & - \\
\hline
\end{tabular}

* Regulation No 1 / 10.10.2007.

$\mathrm{C}_{\mathrm{D}} \leq 1$ - слабо замърсени подземни води; $\mathrm{C}_{\mathrm{D}}=1-3$ - средно замърсени подземни води; $\mathrm{C}_{\mathrm{D}}>3$ - силно замърсени подземни води.

\section{Обект на изследване}

За да се представи нагледно методиката за оценка степента на замърсеност на подземните води е избран мониторингов пункт за подземни води от мониторинговата мрежа на рудник „Адатепе“ край Крумовград (табл. 1). Данните са взети от извършения през 2017 мониторинг ${ }^{1}$, свързан с реализацията на проекта на „Дънди Прешъс Метьлс Крумовград“ ЕАД за добив и преработка на златосъдържащи руди от участьк Адатепе на находище Хан Крум и са свободно достъпни в интернет. Целта на мониторинга е била да се съберат и анализират актуални данни за качеството на подземните води в района на рудника при започването на строителството на минния обект.

Рудник „Адатепе“ е разположен на около $3 \mathrm{~km}$ Ю3 от Крумовград и около $1 \mathrm{~km}$ от р. Крумовица. Той се експлоатира от „Дънди Прешъс Метълс Крумовград“ за добив от 2019 г. по открит способ и преработка на златосъдържащи руди. Строителството на минния обект от „ДПМ Крумовград“ ЕАД с дейности по земноизкопни и насипни работи е започнало през месец ноември 2016 г.

Мониторинговият пункт, представляващ сондаж EGW03, е разположен на надморска височина 312 m, на западния склон на Адатепе и координати в UTM-проекция зона $35 \mathrm{~N}$ : N UTM 35N (WGS84) - 4588201 m, E UTM 35N (WGS84) - 386986 m (фиг. 1). Скалите, изграждащи района, са от палеогенския седиментен комплекс на Крумовградската група (олистостроми, брекчи, брекчоконгломерати, конгломерати, пясъчници, глинести алевролити, въглища, варовици), под който залягат скалите на допалеогенския метаморфен комплекс, изграждащи подложката на участька и разкриващи се в южната и западна част на Адатепе. Метаморфният комплекс е представен от дребно- до среднозърнести предимно двуслюдени гранитизирани гнайси и гра-

\footnotetext{
${ }^{1}$ Доклад за мониторинг на води в района на участьк „Ада тепе“ на находище „Хан Крум“ 2017 г.
}

нитогнайси, гнайсошисти и шисти, амфиболити и др. (Kozhoukharov et al., 1992).

Районът се характеризира като слабо водоносен, с модул на подземния отток около 1,0$0,5 \mathrm{l} / \mathrm{s}_{\mathrm{km}} \mathrm{km}^{2}$ (Berov, 1979). Основно разпространение имат пукнатинните води, подхранващи се от валежите и повърхностния отток. Движението на подземните води е главно по пукнатините на палеогенския и на допалеогенския метаморфен комплекс в посока встрани от хълма Адатепе към p. Крумовица и р. Калджик дере, които са основните дренажни артерии. Мониторинговият пункт сондаж EGW03 служи за проследяване качеството на пукнатинните води от ПВT BG3G00PtPg2023, стичащи се от водосбора на западния склон на Адатепе и дрениращи се към р. Калджикдере. В ПУРБ (2016-2021) ПВТ BG3G00PtPg2023 вече не съществува, а е обединено (заедно с още 18 тела) с ПВТ BG3G000PtPg049 и название Пукнатинни води - Източно Родопски комплекс (фиг. 1). Подземните води са привързани към изветрителните и напуканите зони на скалите и посоката на движение е от високите към ниските части на релефа.

\section{Резултат и дискусия}

За изчисляване степента на замърсеност на пукнатинните води от района на Адатепе, е използван стандарта за качество на подземни води, а именно данните са сравнени с Приложение № 1 към чл. 10, ал. 2, т. 1 на Наредба № 1 (Regulation No 1 / 10.10.2007) за проучване, ползване и опазване на подземните води. От получените резултати (табл. 1) може да се направи извода, че по степен на замърсяване подземните води от ПВТ BG3G00PtPg2023 или ПВТ BG3G000PtPg049 (ПУРБ 2016-2021) в района на мониторингов пункт EGW03 на западния склон на Адатепе за 2017 са били силно замърсени $\left(\mathrm{C}_{\mathrm{D}}>3\right)$. Висока степен на замърсяване $\left(\mathrm{C}_{\mathrm{D}}=14,5\right)$ се регистрира в есенния сезон (м. октомври), когато е измерено и най-ниското водно ниво $(7,75 \mathrm{~m})^{2}$. От друга страна химическото състояние за 2010 и 2011 г. на ПВT BG3G00PtPg2023 „Пукнатинни води - Кру-

2 Доклад за мониторинг на води в района на участък „Ада тепе“ на находище „Хан Крум“ 2017 г. 
Фиг. 1. Местоположение на мониторинговия пункт

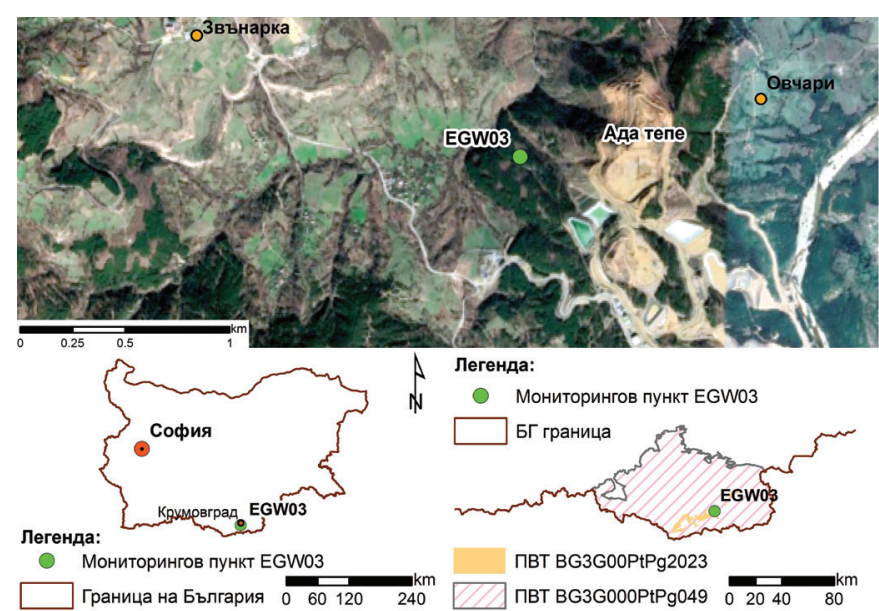

на подземните води. Този индекс ще е от полза на Басейновите дирекции и ще даде възможност при очертаването на подземните водни тела, определени в риск, да се отделят водните тела отчитайки степента им на замърсеност и да се прецени химическия натиск, на който са подложени. Това ще помогне при избор и прилагането на конкретни мерки за подобряване на състоянието им. От прилагането на методиката за района на Адатепе се установява, че по степен на замърсяване подземните води от ПВТ BG3G000PtPg049 в района на мониторингов пункт EGW03 за 2017 са били силно замърсени.

Благодарности: Статията е написана в рамките на Национална научна програма „Опазване на околната среда и намаляване на риска от неблагоприятни явления и природни бедствия“", одобрена с Решение на Министерския съвет № 577/17.08.2018 г. и подкрепена от Министерството на образуванието и науката, Р. България (Споразумение № Д01-322/18.12.2019 г.).

\section{Литература \\ References}

Backman, B., D. Bodiš, P. Lahermo, S. Rapant, T. Tarvainen. 1998. Application of a groundwater contamination index in Finlad and Slovakia - Environmental Geology, 36 (1-2), 55-64.

Berov, L. 1979. Map of the Fresh Groundwater Resources in the People's Republic of Bulgaria on Scale 1:200,000, Map Sheet V-4. Sofia, Committee on Geology.

Kozhoukharov, D., I. Boyanov, A. Goranov, E. Kozhoukharova. 1992. Geological Map of the People's Republic of Bulgaria on Scale 1:100 000, Map Sheet Krumovgrad. Sofia, Committee on Geology, Enterprise of Geophysical Survey and Geological Mapping.

Rapant, S., K. Vrana, D. Bodišand. 1995. Geochemical Atlas of the Slovak Republic. Part 1, Groundwater. Bratislava, Geofond (in Slovak).

Regulation No 1 / 10.10.2007. State Gazette, issue 87/2007. Amended and supplemented, State Gazette, issue 102/23 December 2016) on groundwater research, usage, and conservation, 39 p. (in Bulgarian).

\footnotetext{
3 https://earbd.bg/files/File/Monitoring/Doklad\%20za\%20sastoyanieto $\% 202010-2011 /$ DOKLAD_2010-2011.pdf

${ }^{4} \mathrm{https} / / /$ earbd.bg/DOKLAD̄I ZA SYSTOYANIETO NA VODNITE

TELA_NA_TERITORIYATA_A_NA_IBR-c762

$\overline{5}$ https://earbd.bg/files/File/PURB/PURB\%202016-2021\%20FINAL/Raz deli_pdf/PART\%2004.pdf
} 